\title{
APARIENCIA Y REALIDAD: \\ El uso de la metáfora en The Handmaid's Tale
}

M." Teresa Gibert Maceda

UNED

Entre las múltiples aproximaciones que podemos elegir para abordar el análisis de una obra literaria, cabe destacar el examen del lenguaje metafórico en ella empleado. Como a lo largo de los últimos años se ha venido registrando una auténtica proliferación de este tipo de estudios, no resulta necesario detenerse a exponer pormenorizadamente los postulados teóricos sobre los cuales parece existir un consenso general ${ }^{1}$. Por otra parte, dado que en el anterior volumen de EPOS ya explicamos de manera sucinta los principios esenciales que habiamos tomado como punto de partida para interpretar Life Before Man, ahora evitaremos la reiteración al disponernos a aplicar dichos principios a otra novela de Margaret Atwood ${ }^{2}$. Sin embargo, conviene recordar la idea - comúnmente admitida desde que $\mathbf{J a}$ kobson la formulase por vez primera- de que la metáfora suele predominar en la poesía, mientras que la metonimia generalmente prevalece en las es-

\footnotetext{
1 A los 4.193 titulos publicados sobre esta materia entre los años 1970 y 1985 , que JeanPierre van NoPpen compiló en Metaphor. A Bibliography of Post-1970 Publications, Amsterdam \& Philadephia, John Benjamins, 1985, se han sumado muchos más en su reciente Metaphor II: A Classified Bibliography of Publications from 1985 to 1990. Amsterdam \& Philadelphia, John Benjamins, 1990. Teniendo en cuenta que estas dos bibliografias del profesor Van Noppen constituyen la continuación de la empresa iniciada por Warren SHibles en Metaphor: An Annocated Bibliography and History, Whitewater (Wisconsin), The Language Press, 1971, se observa cómo la metáfora ha recibido una atención constante por parte de la crítica literaria de la segunda mitad del siglo XX.

2 M." Teresa GIBERT MACEDA, «Metáfora en lo alto de los cielos, metáforas al fondo de la calle: El uso de la metáfora en Life Before Man, de Margaret Atwood», en EPOS, VI, 1990, pp. $511-20$.
} 
cuelas literarias realistas y en los escritos redactados en prosa ${ }^{3}$. No obstante, al comentar Life Before Man, pudimos constatar que en ese magnifico ejemplo de prosa realista sucede precisamente lo contrario de lo habitual: se desarrolla el polo opuesto a la metonimia, es decir, predominan de manera inequívoca las metáforas. En concreto, llegamos a la conclusión de que en Life Before Man las situaciones y los objetos domésticos por una parte y por otra los seres míticos constituyen la principal fuente de unas metáforas que sirven para poner de relieve la banalidad de nuestra experiencia cotidiana frente a la belleza del mundo de la imaginación. Este mismo contraste entre fantasía y realidad - tema recurrente en la obra de Atwood- vamos a encontrarlo también, aunque bajo unas formas distintas y con otras connotaciones, al analizar los procesos metafóricos de The Handmaid's Tale.

Al igual que ocurre en las demás novelas de Atwood, la metáfora central de la narración ya aparece en el título ${ }^{4}$. La palabra clave es Tale, el «cuento» que nos relata la protagonista. Ella misma expresa varias veces el deseo de que sus terribles experiencias no sean más que una story o un fairy tale, que pertenezcan al mundo de la ficción, porque sólo engañándose a sí misma se siente capaz de soportar el horror del mundo real (cfr. pp. 19, 49 y 224) ${ }^{5}$.

The Handmaid's Tale se sitúa en un futuro próximo - finales del siglo $\mathrm{XX}$ o comienzos del XXI- $\mathrm{y}$ en el territorio que actualmente ocupan los Estados Unidos de América. Allí, tras el asesinato del presidente de la nación en un golpe de Estado, se instaura un régimen político basado en el terror, que niega los derechos humanos básicos y controla las vidas de los súbditos. En esta tirania de inspiración teocrática, la sociedad está dividida en clases. Los Comandantes forman la clase dirigente. Un rango inferior de la escala social ostentan los Ojos (una especie de policía política) y los Guardianes, encargados de mantener el orden en el interior del país al tiempo que prestan diversos servicios en las casas de los Comandantes, mientras que los Angeles luchan contra los enemigos exteriores. Las mujeres quedan clasificadas en los siguientes grupos: Esposas, Tías, Criadas, Marthas, Econoesposas y No-Mujeres. Cada uno de estos grupos debe observar un estricto código de conducta mediante el cual todo queda reglamentado, desde las funciones principales hasta los mínimos detalles referentes al color de la ropa, sin exceptuar siquiera a los Comandantes, quienes se han atribuido a sí mismos el negro, símbolo de prestigio.

Las Esposas, que por estar casadas con los Comandantes gozan de ciertos

3 Roman JakoBSON, «Two Aspects of Language and Two Types of Linguistic Disturbances", en R. Jakobson \& Morris Halle, (eds.), Fundamentals of Language, The Hague, Mouton, 1956, pp. 55-82.

Pensemos, por ejemplo, en el pastel con forma de mujer de The Edible Woman, las imágenes de inmersión en Surfacing y las de mutilación en Bodily Harm.

Las referencias de las páginas corresponden a la siguiente edición: Margaret ATwOOD, The Handmaid's Tale, London, Virago, 1987. 
privilegios, visten de azul. A las Tías, cuyo color característico es el caqui, se les encomienda el adoctrinamiento de las Criadas y realizan trabajos típicos de una policía femenina. Las Criadas van ataviadas de rojo. Las Marthas realizan las tareas domésticas en las casas de los Comandantes y llevan ropa de color verde. Las Econoesposas, que cumplen los cometidos propios de la mayoría de las mujeres de la etapa anterior (cuidar la casa, atender a sus maridos y tener hijos), se cubren con trajes tricolores; suman el azul de las Esposas al rojo de las Criadas y al verde de las Marthas. Por último, las No-Mujeres están relegadas al final de la escala, castigadas por su incapacidad de ser útiles al sistema o por su oposición al régimen; dado que ni siquiera son dignas de habitar en Gilead, son expulsadas a las Colonias, donde realizan trabajos penosos y sufren innumerables padecimientos.

De dichos grupos sociales, el más extraño en esta peculiar república es el que componen las Criadas. Puesto que la radioactividad ha contaminado el medio ambiente hasta el punto de convertir en estéril a casi toda la población, las funciones reproductoras de la clase dirigente -que las Esposas ya no están en condiciones físicas de ejercer - se han asignado a un reducido colectivo de mujeres cuidadosamente preparadas y controladas para ello. El precedente histórico de las Criadas se halla en la Biblia donde, para sorpresa de muchos, hallamos los dos primeros ejemplos documentados de lo que hoy llamamos las «madres alquiladas». Según el Génesis (30: 1-13), Raquel pidió a su esposo Jacob que le diera hijos a ella yaciendo con su sierva y permitiendo que esta última pariese sobre las rodillas de la propia Raquel. Aunque Jacob ya tenía hijos legítimos de su primera esposa (Lía), accedió a los deseos de la segunda, y así la sierva Bala dio a luz a Dan y a Neftalí. Cuando Lía dejó de ser fértil durante un intervalo de tiempo, empleó el mismo procedimiento con su sierva Zelfa, de quien nacieron Gad y Aser.

Basándose en estos dos ejemplos bíblicos, los dirigentes de la moderna República de Gilead justifican moralmente la existencia de las Criadas. Una vez completada su formación en el Centro Rojo (oficialmente denominado "Centro de Raquel y Lía»), se les da hasta tres oportunidades para quedar embarazadas en un máximo de tres casas distintas, en las cuales van tomando sucesivamente como nombres los patronímicos derivados de los Comandantes. En consecuencia, en el hogar de un Comandante llamado Frederick siempre habrá una Offred, en el de uno llamado Glen habrá una Ofglen, en el de Charles una Ofcharles y en el de Warren una Ofwarren. Si en el espacio de dos años una Criada consigue tener un niño sano, éste pasa a ser el hijo legítimo del Comandante y su Esposa; pero, si al cabo de tres intentos la Criada no cumple satisfactoriamente con su misión, entonces será tachada de No-Mujer y deportada a las Colonias, donde hallará una muerte segura. 
La protagonista de la novela se llama Offred porque está prestando sus servicios en casa de un Comandante llamado Frederick, el tercero y último para ella. Como sucede con el resto de las Criadas, ha perdido su antiguo nombre ${ }^{6}$ y carece de libertad para leer o escribir. Su capacidad de hablar queda restringida a varios saludos rituales y a responder escuetamente a las Esposas, sin poder formular nunca preguntas ni conversar por el placer de hacerlo. En cuanto a su pensamiento, en teoría la imaginación de una Criada tampoco debe rebasar los limites marcados durante la etapa de adoctrinamiento, que tiene como objetivo la absoluta supresión de su identidad. En el nuevo sistema, Offred se ha visto privada de todo lo que poseía: seres queridos (madre, esposo, hija y amistades), puesto de trabajo y pertenencias. Algunas mujeres que se hallan en idéntica situación aceptan resignadamente ese triste destino; otras prefieren tratar de escapar, aunque para muchas la única salida sea el suicidio.

Cuando ya no le queda nada tangible de su existencia anterior, Offred descubre que el lenguaje será su tabla de salvación. Desafiando las múltiples prohibiciones impuestas por las autoridades, conseguirá darnos a conocer su testimonio gracias a unas cintas magnetofónicas en las cuales va grabando de manera fragmentaria los recuerdos de su pasado mezclados con el relato de su vida presente. Así surge el Cuento de la Criada, a través del cual Offred logra hacernos llegar su mensaje, pervivir, dejar su huella en la historia. Además, la narración le permite conservar el equilibrio mental, afirmar su personalidad y hasta cierto punto recuperar interiormente su identidad perdida. Aunque poco pueda hacer para decidir su futuro, Offred está decididamente empeñada en durar (p. 17) y sabe que, en esas dificiles circunstancias, sólo las palabras le ayudarán a subsistir durante el tiempo de vida material que le concedan y, tras su muerte, quedarán fijadas en algún lugar. Por consiguiente, no resulta extraño que ella haga un uso crtremadamente cuidadoso del lenguaje, disfrute reflexionando sobre determinados fenómenos lingüísticos (por ejemplo, la polisemia y la etimología de algunos términos) y se recree con juegos verbales. En particular, la elección de las metáforas empleadas por Offred parece obedecer a decisiones tomadas de manera consciente y no arbitraria.

El relato de Offred se extiende a lo largo de trescientas páginas, publicadas ulteriormente con unas notas de un supuesto editor, el Profesor Pei-

- Aunque el profesor Peixoto al presentar el relato no se interese por descubrir el nombre original de Offred, ella lamenta esa pérdida. Tras múltiples elucubraciones en torno al tema, prefiere ocultarlo como si fuera un amuleto (p. 94). No obstante, deja una clave cuando menciona a cinco futuras Criadas que se comunican en el dormitorio del Centro Rojo. Dado que las cuatro primeras se distinguen a lo largo del relato como mujeres diferentes de Offred, parece lógico que el último nombre citado le corresponda a ella misma, junto al de Moira, su mejor amiga. June sería su "nombre brillante», que ella asocia con septiembre, es decir, la denominación de otro mes del año (p. 94). 
xoto, quien cierra la novela explicando las circunstancias en que se efectuó el hallazgo arqueológico y elucubrando sobre la verdadera identidad de los personajes. Aunque el Profesor toma la palabra en las trece últimas páginas de la novela, Margaret Atwood pone en su boca una sola metáfora, llena de ironía en una obra de clara inspiración feminista: el pasado se compara con una matriz desde la cual nos llegan ecos que no siempre sabemos descifrar (p. 324).

En lo referente al lenguaje metafórico de Offred, lo más llamativo es el persistente contraste entre las imágenes apacibles que sirven para enmascarar una realidad violenta y los símiles terroríficos que se emplean para describir objetos o sucesos que en sí nada tienen de agresivo. En otras palabras, lo desagradable o amenazador se visualiza como algo plácido, mientras que lo neutro y carente de riesgos se percibe como repugnante o peligroso. Los dirigentes de esta singular república utilizan un lenguaje metafórico mediante el cual tratan a los súbidos como niños y sistemáticamente encubren sus actuaciones sangrientas con simbolos pacificadores. Era de esperar que la protagonista - tras haber sido sometida a un lavado de cerebro por parte de las Tías - adoptase los recursos lingüísticos de sus opresores. Por consiguiente, ella misma se refiere a situaciones espantosas con términos tranquilos, con frecuencia mediante metáforas extraídas de la vida cotidiana y preferentemente relativas al mundo infantil, de los juegos y de los cuentos de hadas. El efecto que estos reiterados contrastes producen sobre los lectores de la novela resulta aterrador.

El deseo de presentar como atractivo lo que es por sí mismo repelente conduce a los gobernantes a llamar Angeles a los soldados, Guardianes a los policías encargados de una represión brutal, y Tías a las autoritarias mujeres responsables del severo adoctrinamiento de las Criadas. Fieles a las consignas del sistema, las Tías suelen llamar a las Criadas «niñas» (p. 39) -a veces incluso uniñas mimadas» (p. 99)- hasta alcanzar su objetivo, consistente en que unas mujeres adultas se comporten y se vean a sí mismas como seres inmaduros, desvalidos, necesitados de guía, sin responsabilidad, sometidos a la autoridad de un Estado en apariencia paternal?

La propia Offred, cuya mente ha sido remodelada, compara a las Criadas con niñas revoltosas (p. 20) y con colegialas (p. 36 y 224). Ella misma se siente tratada como una niña a quien los mayores ocultan información (p. 63) o alguna vez le permiten acostarse tarde (p. 92). También describe algunas acciones suyas calificándolas de infantiles; por ejemplo, la de caminar por la calle evitando pisar las rayas del suelo (p. 34), o la de levantarse por la noche para mirar por la ventana de su cuarto (p. 108). Especialmente en sus relaciones con el Comandante a quien sirve, Offred se ve más como

\footnotetext{
${ }^{7}$ Obsérvese que, cuando las Tías se dirigen a las Esposas, las llaman «señoras" (ladies, p. 286).
} 
una niña que como una criada. Así, cuando él la manda llamar a su despacho, ella acude igual que una alumna convocada por el director de la escuela (p. 146) y después ambos juegan al scrabble como una pareja de niños (p. 163). Estos juegos infantiles que el Comandante ha practicado ya con las anteriores Criadas (p. 197) están rigurosamente prohibidos y constituyen un serio peligro para Offred, pero a ella le parecen simples travesuras, como entrar tarde en el dormitorio de un internado (p. 149). Y, cuando el Comandante acaricia la mano derecha de Offred durante una arriesgada salida nocturna de ambos, a ella se le ocurre comparar el gesto con el de dos adolescentes haciendo manitas en el cine (p. 244). Otra actividad igualmente comprometedora - consistente en hablar con una compañera sobre una posible escapatoria - es para la protagonista una mera diversión, como los secretos que se comparten en el colegio, o como leer novelas de espionaje en lugar de hacer los deberes o quedarse a ver la televisión por la noche (p. 212). Una aventurada propuesta de la Esposa, que sería castigada con la pena de muerte si ambas fueran descubiertas, le parece a Offred una estratagema infantil (p. 215). También el hecho de tener que pedir cosas tan simples como una loción para las manos y una cerilla -objetos de los que se priva a las Criadas- le hace sentirse como una menor de edad (pp. 167 y 218).

En esta extraña sociedad, no sólo las Criadas son equiparadas a niñas; todos los teleespectadores son tratados como tales por parte de un presentador con cara de abuelo (p. 93) e incluso los médicos - a quienes no se les ha permitido asistir al parto de Janine - tienen la mirada decepcionada de los niños enfermos a quienes se obliga a quedarse en casa (p. 137). Pero, de todas las analogías infantiles, las dos más chocantes se refieren al responsable de un campo de exterminio que - siendo un monstruo para la mayoría de las personas- para su indulgente amiga era un "niño grande" y, por último, la concerniente a la Criada que se ha ahorcado y que Offred imagina como una niña balanceándose agarrada a una rama (pp. 155 y 223).

Otras metáforas relacionadas con el mundo infantil se aplican a situaciones de idéntica violencia. Por ejemplo, cuando Offred contempla los cadáveres de los ajusticiados con las cabezas cubiertas por bolsas blancas, le recuerdan unos muñecos con las caras sin pintar, espantapájaros u hombres de nieve que han perdido sus ojos de carbón y la zanahoria que les habian colocado a modo de nariz (p. 42). A través de una de las bolsas se ha filtrado la sangre, formando una especie de boca pintarrajeada de rojo como las que pintan los niños con gruesos pinceles en los jardines de infancia; el gesto es el de una macabra sonrisa (pp. 42 y 53). Resulta paradójico comprobar cómo en un mundo del que han desaparecido casi todos los niños existe una auténtica obsesión por evocar su existencia, mediante el uso de metáforas relacionadas con ellos.

Las mujeres oprimidas y manipuladas se asemejan a muñecas de diversos 
tipos. Offred y Ofglen, que sufren psiquica más que fisicamente, actúan como autómatas. Por ejemplo, la primera se escucha a sí misma como si fuera una muñeca parlante respondiendo con voz monótona (p. 26) y la segunda gira como una figura sobre ruedas o sobre una caja de música ( $p$. 53). Durante la etapa de transición política, cuando Offred comenzó a verse privada de derechos y regresó a casa habiendo perdido su puesto de trabajo, pensó que su marido la abrazaba igual que si fuera una muñeca (p. 191). Por su parte, las prostitutas (que no reciben ninguna denominación metafórica dentro del sistema, porque oficialmente no existen) parecen muñecas de carnaval (p. 265). La Criada Janine (ahora llamada Ofwarren), poco antes del parto, está encogida a la manera de una muñeca vieja abandonada en un rincón (p. 134). Sin embargo, la Esposa del Comandante - llamada Serena - no tiene el ademán de una muñeca, sino la rigidez de una efigie; y se diría que está hecha de madera o de hierro (pp. 106 y 216).

Además de identificarse con muñecas, al ser las Criadas objeto de reiterada manipulación, Offred las compara con las ratas de laboratorio en un laberinto o con las palomas en un experimento psicológico (pp. 174 y 79 80 ). Janine -que al llorar parece un ratón recién nacido (p. 82)- acaba adoptando el comportamiento propio de un cachorro maltratado, capaz de hacer cualquier cosa a cambio de un instante de aprobación (p. 139). La sustitución de cada Criada por una nueva en los hogares de los Comandantes equivale a la de los perros por parte de sus dueños (p. 197). Offred se ve a sí misma como un animal doméstico con las orejas estiradas y dispuesto a hacer trucos para gustar al Comandante, o como un gatito en un escaparate al que se contempla sin intención de comprarlo (pp. 193 y 148). En cuanto al tatuaje que lleva en el tobillo, le hace sentirse un ejemplar de ganado con la marca de su dueño (p. 266).

Resulta lógico que Offred asimile a los perseguidos con animales víctimas, tema recurrente según Atwood en la Literatura Canadiense y, sin duda, central en su propia obra. Así, Offred imagina a su marido Luke como un animal enjaulado, y al hombre que sufre el linchamiento como una rata moribunda arrastrándose por el suelo de la cocina (pp. 115 y 291). También sospecha que el cadáver de Luke pudiera estar secándose al sol igual que una medusa sobre la arena (pp. 115). Inmediatamente después de la ejecución, los cuerpos de las tres mujeres ahorcadas están colgados a la manera de unos pollos en el escaparate de una carnicería; pero, cuando son expuestos en el Muro, con el paso del tiempo sus ropas pierden el brillo y el apresto, por lo cual les dan la apariencia de mariposas muertas o peces tropicales extendidos sobre la tierra (pp. 289 y 295). En cambio, la camioneta de los vigilantes avanza como un tiburón al acecho, y los guardias miran como si fueran halcones (pp. 178 y 260).

El uso de tales imágenes animales - correspondientes a verdugos y víctimas- nada tiene de sorprendente. Ahora bien, resulta chocante el procedimiento contrario, mediante el cual se aplica una metáfora violenta o 
desagradable para describir algo apacible o placentero y, a la inversa, una metáfora hermosa para embellecer algo hiriente. Por ejemplo, el hueco que ha quedado en el techo al descolgar una lámpara trae a la mente de Offred la imagen de un rostro al que se le hubiera arrancado un ojo (p. 17). Los tulipanes rojos se convierten a través de The Handmaid's Tale en la flor simbólica de la sangre y el dolor, a causa del lenguaje metafórico que Offred utiliza cada vez que los menciona (pp. 22, 43, 55, 115, 160 y 161).

Con respecto a los objetos domésticos y a las situaciones cotidianas, Offred a menudo emplea un lenguaje de extrema dureza, lleno de símiles extraídos de la jerga militar, en el que abundan las referencias a guerras, ejércitos, ataques, banderas y armas. Durante el adoctrinamiento - una experiencia de tipo castrense (p. 17)- las Tías comparaban a las Criadas con fuerzas de choque avanzando a través de un territorio peligroso ( $\mathrm{p}$. 122). En este sentido, Offred va todavía más lejos cuando lamenta que su relato contenga tanto dolor y esté hecho pedazos al igual que un cuerpo atrapado en un fuego cruzado o desgarrado violentamente (p. 279). En su mente atormentada, el simple sonido metálico de la cerradura en la puerta de la cocina le recuerda el ruido de una ratonera o de un arma (p. 280). Por el contrario, intenta visualizar lo que en sí es realmente cruel como algo intranscedente o incluso atractivo. Así, los disparos a su espalda le hacen evocar unos fuegos artificiales y el crujir de una rama seca quebrándose ( $p$. 85). En otros momentos, lo agresivo parece irreal, perteneciente al ámbito del teatro o de los relatos de ciencia ficción: los hombres armados que derrocaron al gobierno surgieron como marcianos (p. 186).

Offred cuenta el terrible ajusticiamiento de tres mujeres utilizando analogías que en otro contexto no resultarian dolorosas, pero que en éste aumentan la angustia de los lectores. El escenario se ilumina como si de un belén navideño se tratase; las tres mujeres aguardan sentadas como si fuesen unas alumnas esperando los premios en una ceremonia de graduación; $y$, por último, momentos antes de ser ejecutada, una de ellas recibe ayuda para subir al estrado como si estuviera montando en un autobús (pp. 285, 286 y 288). El movimiento de las ahorcadas se percibe como una danza y sus cuerpos como los de unas bailarinas (pp. 289 y 298). Para iniciar el horrendo linchamiento del hombre, suena un silbato que evoca un partido de voleibol y la gente se agolpa como los espectadores al comenzar un concierto de rock (p. 291). Al final del relato, quienes van a detener a Offred tocan el timbre de la casa como lo haría una vendedora de cosméticos (p. 305).

Aparte de los ya mencionados, otro grupo de metáforas que merece atención está formado por las que Offred se aplica a sí misma para percibirse y de ese modo buscar su identidad perdida comparándose con objetos a su alcance o con elementos exóticos. Por ejemplo, al recordar que su madre le aconsejaba vencer las dificultades fortaleciéndose como el acero, medita sobre el alcance de la frase y consigue recobrar ánimos (p. 169). En el pasado solía creer que su cuerpo era un instrumento, pero ahora prefiere pensar 
que es una ciénaga o terreno pantanoso en el cual únicamente ella sabe dónde poner los pies (p. 83). En momentos especialmente difíciles, trata de superar la tensión bromeando; cuando se apresta para la desagradable ceremonia de la fertilización, observa que está como un cerdito en un concurso, lavado, cepillado y bien alimentado (p. 79). También utiliza la ironía a modo de calmante para el sufrimiento cuando comenta que, extendida en la cama después de haberse aplicado un poco de mantequilla para evitar la sequedad de la piel, parece una tostada (p. 108). Pero no en todas las ocasiones está presente el sentido del humor. A veces, los símiles intensifican su percepción de la angustia, la inquietud o el dolor. El miedo le provoca la sensación de ser un trozo de algodón de azúcar, que si alguien apretara entre sus manos, quedaría reducido a una bolita húmeda (p. 148). Cuando los visillos le tocan la cara, se imagina que es un espectro con el rostro amortajado (p. 180). Especialmente amarga le resulta la idea de no ser ya para su hija más que la sombra de una sombra, y saber que su imagen ha sido borrada de la mente de la pequeña, como una mujer de arena abandonada al borde del agua por un niño incauto (p. 240).

Algunas de las metáforas que Offred se aplica son convencionales. Por ejemplo, ella constituye para Serena un simple mueble sobre el que apoyarse al pasar (p. 89). Para el Comandante, Offred no tiene más importancia que un jarrón o una ventana (p. 171) aunque, cuando el hombre la mira con curiosidad, la Criada piensa que se ha convertido en un puzzle (p. 194). Sin embargo, otras metáforas resultan sorprendentes: Offred se compone como si fuera un discurso porque debe presentarse como algo hecho y no nacido (p. 76); también - al considerarse una refugiada del pasado- se asemeja a un ruso blanco tomando el té en París, anclado en el siglo XX (p. 239). Cuando se compara con animales, suele elegir los domésticos (pp. 108, 148 y 193). Ahora bien, al pensar que debe tener un niño para justificar ante las Marthas el gasto de comida y atenciones, se ve como una hormiga reina (p. 145). Y, con una mezcla de tristeza e ironía, observa cómo - al acariciar el Comandante el ridículo vestido de plumas con el que la ha disfrazadoella se siente un pájaro muerto (p. 267).

Aunque Offred es consciente de que se debilita al identificarse con símbolos frágiles, con frecuencia cede ante esa tentación. Por ejemplo, al evocar la fracasada tentativa de huir con su marido y su hija, recuerda cómo Luke le dijo que estaba blanca como una sábana y ella inmediatamente derivó de tal comentario una larga serie de conceptos negativos que aumentaron su vulnerabilidad (p. 95). No sólo se cercioró de que estaba pálida, sino que además se asimiló a la sábana en cuanto objeto liso, delgado y transparente. Entonces, mediante un complicado proceso mental, se convenció a sí misma de que los controladores descubririan sus verdaderas intenciones y de ese modo precipitó el triste desenlace.

De una manera igualmente elaborada, Offred va remodelando el símil que durante el adiestramiento le inculcaron las Tías, según el cual las Cria- 
das son vasijas sagradas o cálices ambulantes (pp. 75, 107, 146, 172 y 298). En su origen, la metáfora servía para poner énfasis en el carácter religioso de la misión materna de las Criadas, pero Offred acaba dándose cuenta de que esa comparación constituye una artimaña para embellecer el mero uso instrumental al que son reducidas unas mujeres forzadas a tener hijos para otras. Otro ejemplo de metáfora que las Tías aplicaban a las Criadas, con el fin de hacerles más grato su cometido, era considerarlas perlas; pero Offred también reflexiona sobre la analogia y contrarresta el efecto positivo que pudiera tener cuando observa que las perlas no son sino esputos congelados de las ostras (p. 124).

Ahora bien, Offred no siempre desenmascara las argucias de unos dirigentes empeñados en engañar a sus súbditos. A veces ella misma utiliza un procedimiento idéntico. Su cuerpo es una nube en torno a un objeto central con forma de pera, grande y oscuro como el cielo nocturno sobre el cual brillan innumerables estrellas; cuando la luna cruza el firmamento y desaparece, Offred se siente embargada por la tristeza. Aunque no haya ninguna mención explícita de las palabras útero, óvulos o menstruación, es inequívoca la referencia a los embarazos frustrados (p. 84).

Todo lo relativo a la fertilidad y al sexo recibe un tratamiento metafórico a lo largo de The Handmaid's Tale, según es habitual en las novelas de Atwood. Otras facetas características del discurso de la autora también se reflejan aquí. Por ejemplo, el predominio de lo visual sobre los demás sentidos en la elaboración de las analogías, la escasez de metáforas mecánicas frente a la abundancia de las derivadas de la naturaleza (animales y plantas), las metamorfosis de las personas, etc. En definitiva, el lenguaje metafórico de esta obra tiene mucho en común con todas las demás de Margaret Atwood. Lo único realmente singular es la forma en que se efectúa el persistente contraste entre apariencia y realidad, mediante la tensión continua entre el deseo de descubrir la verdad que preferimos conocer y la necesidad de ocultar la que no podemos soportar. 